\title{
Economic Impacts of Business Continuity on an Outbreak of Highly Pathogenic Avian Influenza in Minnesota Egg Laying Operations
}

\author{
Jada M. Thompson ${ }^{1, \star}$, Dustin L. Pendell ${ }^{2}$, Tim Boyer ${ }^{3}$, Kelly A. Patyk ${ }^{3}$, Sasidhar Malladi ${ }^{4}$ and \\ J. Todd Weaver ${ }^{3}$
}

\begin{abstract}
${ }^{1}$ Department of Agricultural and Resource Economics, University of Tennessee, Knoxville, Tennessee, USA, ${ }^{2}$ Department of Agricultural Economics, Kansas State University, Manhattan, Kansas, USA, ${ }^{3}$ U.S. Department of Agriculture, Animal and Plant Health Inspection Service, Veterinary Services, Science Technology and Analysis Services, Center for Epidemiology and Animal Health, Fort Collins, Colorado, USA and ${ }^{4}$ Center for Animal Health and Food Safety, University of Minnesota, Minneapolis, Minnesota, USA

*Corresponding author. Email: jthom207@utk.edu
\end{abstract}

\begin{abstract}
Animal disease outbreaks can cause disruptions in domestic and international markets. Business continuity aims to provide a proactive approach to alleviate some of these negative effects on consumers, producers, and agribusinesses. Using a partial equilibrium model of the U.S. egg industry, the economic impacts of business continuity during an epidemiological simulated disease event are modeled. Results show total welfare losses can be reduced by allowing permitted movement during an outbreak given a specified level of biosecurity. Understanding the potential market responses business continuity can have on the market may lead to reductions in the negative implications of a disease event.
\end{abstract}

Keywords: Avian influenza; business continuity; disease spread modeling; partial equilibrium modeling

JEL Classifications: Q13; Q180

\section{Introduction}

Highly pathogenic avian influenza (HPAI) is an extremely contagious viral disease of poultry notifiable to the World Organisation for Animal Health (OIE) (OIE, 2016a). In the event of an HPAI outbreak in the United States, emergency response includes establishing an HPAI Control Area where measures are applied to prevent further spread (OIE, 2016b). A stamping-out policy aimed at quickly eradicating the disease is the primary control strategy for infected or exposed flocks. The application of sanitary measures (i.e., biosecurity) to prevent further spread and surveillance testing to quickly identify new cases are essential components of an outbreak response. Movement restrictions (i.e., stop-movement orders) are also implemented to prevent exposure of disease-free poultry to infectious poultry, or to contaminated poultry products, equipment, and personnel. Movement restrictions may be broadly applied within the HPAI Control Area because of the uncertainty of the true disease status of poultry on operations that appear to be clinically normal. These restrictions limit movement to, from, and within the Control Area in order to minimize the potential spread of disease and act as a quarantine of potentially HPAI-infected premises. This research aims to estimate the economic effects of reducing these movement restrictions on producers, agribusinesses, and consumers during an HPAI outbreak while accounting for possible changes in disease spread. The results provide a risk-based 
methodology for analyzing potential changes in how industry and agencies handle exceptional, business disrupting events.

Guidelines have been established to facilitate international trade for poultry and poultry products between disease-free countries (OIE, 2016a), but when an outbreak of HPAI is confirmed, countries may impose restrictions on international trade of poultry and poultry products. Countries may accept continued trade from areas free of disease, with certification that the poultry and poultry products are derived from poultry shown to be free of HPAI using surveillance and biosecurity procedures outlined in the OIE Terrestrial Animal Health Code (OIE, 2016b). For example, during the 2014-2015 HPAI outbreak in United States, 44 importing countries chose to regionalize trade restrictions to the state and county levels (Seitzinger and Paarlberg, 2016; Thompson, 2018). Typically, countries will prohibit the import of poultry and poultry products, unless subjected to treatments sufficient to inactivate the virus, from within the HPAI Control Area. One interpretation of the OIE guidelines is that these areas would operate independently (Vaillancourt, 2009), where there would be no movement of poultry, poultry products, or poultry-related conveyances between these areas during an outbreak and until disease-free status is achieved. However, an HPAI Control Area may not necessarily contain all the products and services needed to support commercial poultry production, and some products from facilities within the HPAI Control Area are needed to maintain business continuity for the poultry industry outside the Control Area. For example, an egg processor outside of the Control Area that normally has eggs supplied from the surrounding area, including eggs from within the Control Area, could face shortages of supply not just from disease but also from limited product movement. Although movement restrictions may be effective at limiting outbreak spread from within the HPAI Control Area, prolonged movement restrictions may result in unintended consequences for producers and consumers such as loss of income, restriction in the supply of egg products, increases in consumer retail prices, or destruction of perishable products. On the other hand, movement of some higher-risk products, in the absence of appropriate biosecurity measures, could pose a risk of increasing the HPAI disease spread, leading to longer outbreak response, increased response costs, larger potential trade losses, and loss of trading partners' confidence in the industry's ability to contain the disease.

Business continuity planning aims to mitigate economic losses attributable to animal disease outbreak response by facilitating normal business operations through the managed movement of disease-free animals and noncontaminated animal products (Moore and Allen, 2013). The approach can achieve a balance between strict control measures intended to bring the outbreak under control as quickly as possible and minimization of the unintended economic consequences to producers and consumers. Since 2006, a joint government-industry-academic work group (Egg Sector Working Group) has developed plans for the managed movement of poultry products during an HPAI outbreak (Hennessey et al., 2010). These plans incorporate science- and risk-based control measures that have been evaluated using risk assessment methods. Using these risk assessments, an analysis of the economic implications of the HPAI management policies can be estimated considering both the net social welfare and market effects. Using scenario analysis, an assessment of the direct and indirect consequences of disease spread and the economic implications can be estimated, which is consistent with OIE recommendations for supporting international trade (OIE, 2010).

\subsection{Objective}

The objective of this study is to evaluate the economic consequences of either permitting or prohibiting the movements of shell eggs (more formally referred to as nest-run shell eggs), which have been implicated in indirect HPAI virus transmission in previous outbreaks (Thomas et al., 2005), from commercial egg layer facilities located within an HPAI Control Area (e.g., Minnesota) into areas shown to be free from disease (e.g., the remainder of the United States). Specifically, we evaluate the economic impacts of simulated HPAI outbreaks by quantifying regionalized domestic 
production and market effects. This analysis uses regionalization as a means of preserving international trade for the region of the United States not affected by the outbreak. Using disease spread data derived from an epidemiological disease spread model that accounts for any potential increases in disease transmission, a partial equilibrium model of the U.S. egg industry is constructed to assess the impacts of product movement, as well as the ability of regionalization to meet domestic needs.

As the first study to estimate the economic impacts of business continuity during a regionalized animal health event, this analysis opens the dialog for communicating the economic benefits and costs of business continuity to agribusinesses, producers, consumers, and policy makers. Economic assessment of permitted movements will provide government and industry decision makers an ex ante evaluation of the potential plausibility and effectiveness of an outbreak response strategy that provides agribusinesses with business continuity.

\section{Background}

The U.S. egg industry operates with a just-in-time delivery system with very limited storage capacity (48 to 72 hours) for some perishable products (U.S. Department of Agriculture, National Agricultural Statistics Service [USDA-NASS], 2014). U.S. table egg layer production is predominantly managed under contract farming in the United States (79\%), and under this system, producers are responsible for facilities and management of layer birds (MacDonald and Korb, 2011; U.S. Department of Agriculture, Animal and Plant Health Inspection Service [USDA-APHIS], 2014). Producers are compensated on the number of eggs produced. Egg layers produce either hatching eggs or shell eggs. Hatching eggs are excluded from this analysis as they are produced through special breeder houses and are not substitutable at the market level for consumption eggs. Shell eggs are diverted into table eggs or breaker eggs, which are further processed into final consumption products. Prior to packaging into cartons, table eggs must be processed (i.e., graded, washed, and sanitized). These cartons are then shipped to retailers or final consumers. Breaker eggs are broken and processed into liquid, dried, or frozen eggs. These egg products can be packaged and sold as processed eggs or used as inputs in other food products. For this study, liquid, dried, and frozen eggs are aggregated into one group called "processed eggs." Producers who wash and sanitize shell eggs on-farm represent a relatively small segment of the egg industry. There are no reported numbers of these producers because of privacy in reporting, but they represent a smaller subset of the $6.2 \%$ of layer producers with more than 200,000 birds that would be large enough to justify on-site processing creating a separate supply chain (USDAAPHIS, 2014). As such, these firms are excluded from this analysis of shell eggs because of separability of these products along the supply chain, different production structures, lack of data, and differing risks associated with product movement.

Outbreaks of HPAI in commercial poultry can have many economic impacts on producers, processors (integrators), and consumers, as evidenced by the 2014-2015 outbreak of HPAI in commercial poultry in the United States. In that outbreak, more than 48 million birds were affected, of which $67 \%$ were laying hens and the remaining $33 \%$ were commercial turkeys (USDA, 2015). This was the largest animal disease event in the United States, affecting domestic supplies and prices (Huang, Hagerman, and Bessler, 2016), as well as international trade, with 44 trading partners implementing regional trade restrictions (Seitzinger and Paarlberg, 2016; Thompson, 2018). Although the poultry industry was able to restock bird densities, the response to HPAI management paved the way for business continuity and policies that support it (Thompson and Pendell, 2016).

The use of partial equilibrium modeling has been used heavily in studies of disease event impacts because of its tractable nature and ability to estimate economic implications prior to a disease event (Djunaidi and Djunaidi, 2007; Paarlberg, Seitzinger, and Lee, 2007; Johnson and Pendell, 2017). Johnson et al. (2014) estimated the potential economic impacts of a simulated HPAI outbreak on the Texas supply chain for broilers, turkeys, and egg production. That study 
estimated the impacts of regionalization (i.e., a separation of a specific section of geography from the rest of the United States [ROUS]). In their work, Texas was regionalized during an HPAI outbreak. When trade restrictions were concentrated on Texas, the impacts of HPAI were lessened on the ROUS.

\subsection{Business continuity and the associated risks}

Business continuity planning is a means for agribusinesses and allied industries to prepare for unplanned events so that they can operate with the least disruption during these events (Zsidisin, Melnyk, and Ragatz, 2005). This preplanning for animal disease outbreaks can potentially alleviate business strains through proactive permitting processes to facilitate movement of products (Moore and Allen, 2013; Thompson and Pendell, 2016). Because of the risk associated with moving shell eggs, specific HPAI control measures were proposed by stakeholders to reduce the risk of spread between facilities during business continuity planning. Briefly, these measures include testing a sample of poultry daily from the flock of origin for the presence of HPAI, prohibiting the movement of shell eggs to egg processing facilities where live poultry are present, using disposable egg handling materials, and using specific protocols for cleaning and disinfection of surfaces in the processing facilities. To facilitate business continuity planning decisions for the movement of egg industry products, risk assessment methodology is used to evaluate the performance of surveillance testing protocols and other biosecurity measures for moving shell eggs in order to assess the effectiveness of risk reduction. Given the strict implementation of product-specific HPAI control measures, permits may be issued to move shell eggs outside the Control Area from Monitored Premises, or those premises that test negative and are not known to be infected.

To address the risks associated with business continuity practices, the Egg Sector Working Group estimated the potential risk of HPAI spread given movement of various poultry products from premises located in close proximity to a known infected premise during an outbreak to create a set of proactive risk assessments, included in the Secure Egg Supply (SES) Plan to support rapid permitting decisions to promote food security; protect animal health; ensure continuity of markets and the consumer egg supply; and foster government, industry, and consumer confidence. These assessments adhere to the OIE's international standards and guidelines for risk analysis (OIE, 2013a, 2013b).

Components of a proactive risk assessment include entry assessment, exposure assessment, consequence assessment, and risk estimation. Entry assessments describe the pathways in which a pathogen, such as HPAI, can be introduced to an environment. Exposure assessments estimate the likelihood of disease transmission, or exposure occurring through different vectors. For HPAI, these assessments estimate the disease spread risks associated with product movement inside and outside of Control Areas. Entry and exposure assessments have been estimated for eight egg commodities including shell eggs (USDA-APHIS, 2013). This research builds on these risk assessments to create a consequence assessment, or a rigorous assessment of the direct and indirect impacts, for business continuity during a disease outbreak. The risk estimate is a combination of the first three assessments to generate a complete risk estimation for business continuity (OIE, 2013a, 2013b; Thompson and Pendell, 2016).

Many factors should be considered in deciding whether it is feasible to allow a movement permit system during an HPAI outbreak. These factors include the probability of the increased exposure of susceptible poultry because of product movement, the likely social and economic consequences of this increased exposure because of product movement, and the social and economic impacts if austere movement restrictions are implemented. Movement permits can be issued when premises are shown to be free from HPAI and following prescribed biosecurity measures. A movement permit allows for movement of sanctioned products within, into, and out of Control Areas. These permits require premises to test negative for HPAI prior to any movement, with continued testing to ensure disease-free premises (USDA-APHIS, 2013). Additionally, premises must follow 
strict biosecurity measures, which help to reduce disease spread risks. When these requirements are met, premises may be granted movement permits that sanction selected movements off-farm (e.g., eggs and egg products) or on-farm (e.g., animal feed). Each of these additional movements poses a specific level of added risk for the potential spread of HPAI.

\section{Methodology}

This analysis involves two components. First, an epidemiological model is used to estimate the spread of HPAI in the state of Minnesota accounting for additional risk of disease spread, or the probability of disease transmission, given different disease management scenarios. Second, outputs from the epidemiological model are incorporated into a quarterly economic partial equilibrium model. Two outbreak management strategies evaluated in the epidemiological and economic framework include (1) implementing business continuity and (2) not implementing business continuity during a simulated HPAI outbreak in Minnesota.

\subsection{Epidemiological modeling}

Epidemiological models are tools that can be used to study disease dynamics in a population and to evaluate the effectiveness of control measures. InterSpread Plus (Stevenson et al., 2013), a stochastic, spatially explicit epidemiological modeling framework, is specifically parameterized to simulate HPAI spread among commercial broiler, egg layer, and turkey operations in Minnesota. Each flock in the population data set has an associated geographic location, production type, and number of birds. This epidemiological model uses actual commercial flock locations and numbers of birds derived from a database of registered flocks obtained from the Minnesota Pollution Control Agency. A total of 895 flocks, representing approximately 55.7 million birds, are included in the data set. The model simulates disease spread via movement of birds (direct contact); movement of people, vehicles, and other fomites-objects or material likely to carry infection such as clothing or equipment-(indirect contact); and local area spread (i.e., spread associated with distance between premises not attributable to a specific mechanism). Parameter values differed between the scenarios in two key areas: (1) reduced probability of transmission under the business continuity scenario and (2) increased detection of infected premises for the business continuity scenario. The parameter values, outlined in online supplementary Appendix A, represent differences in biosecurity and diagnostic testing that would be required to support shell egg movements for permitting under the SES Plan. Control measures implemented in the model for both scenarios include the following: depopulation of infected premises, tracing of contact premises, creation of Control Areas, and movement controls for premises located within Control Areas (i.e., infected and detected premises are quarantined while all other premises in the Control Area have reduced frequencies of direct and indirect contacts). Model parameters are based on literature, expert opinion, results of a separate model of within-flock spread, and documented response plans (online supplementary Appendix A).

\subsection{Economic modeling}

A quarterly, partial equilibrium model of the U.S. egg industry is developed accounting for the farm, processing, and retail sectors. The economic model developed here follows the broader framework set forth by Paarlberg et al. (2008). The economic model is based on a linear approximation of unknown, underlying supply and demand relationships of the U.S. egg industry. Exogenous shocks are incorporated at each stage in the supply chain in the model. For this work, the simulated effects of HPAI are represented by exogenous shocks to shell egg production. The use of substitution, supply, and demand elasticities (Bell, 2001; Ollinger, MacDonald, and Madison, 2005; U.S. Department of Agriculture, Economic Research Service [USDA-ERS], 2013) provides a framework for transmission of exogenous shocks throughout the model. 
In addition to published elasticities, specific stock, net exports, and price elasticities are calculated by the authors to reflect the differentiated market of table and processed eggs. A description of the economic model is presented subsequently in its fully differentiated form where $E$ is used to represent the relative change operator (i.e., dln). Full details of the complete economic model and parameterization are provided in online supplementary Appendix B. A sensitivity analysis of the parameters found the model robust to changes in the parameters.

$$
E S_{t}=\varepsilon_{s} E P_{s, t}
$$

The model considers the initial shell egg supply $(s)$ in time $t$ to be a function of the producer price of shell eggs and the own-price elasticity of shell eggs $\left(\varepsilon_{s}\right)$ (equation 1).

$$
E S_{t}=E \phi_{t}+\lambda_{s, t e} E q_{t e, t}+\lambda_{s, p e} E q_{p e, t}+\lambda_{s, t e} E a_{s, t e, t}+\lambda_{s, p e} E a_{s, p e, t}
$$

Additionally, allocation of shell eggs is a function of the quantity of eggs demanded $\left(q_{i}\right)$ for type $i$ (te, table eggs, or pe, processed eggs) and the per-unit derived demand for eggs $\left(a_{s, i}\right)$ for time $t$. The factor share of production is represented by $\lambda_{s, i}$. Exogenous shocks to the egg supply, such as depopulated poultry because of HPAI, can be applied using $\phi$.

$$
E D_{i, t}=E \gamma_{i, t}+\varepsilon_{i, i} E P_{i, t}+\varepsilon_{i, j} E P_{j, t}
$$

Domestic retail demand for egg type $i$ in time $t$ is a function of own $\left(P_{i}\right)$ and cross $\left(P_{j}\right)$ prices and own-price $\left(\varepsilon_{i, i}\right)$ and cross-price $\left(\varepsilon_{i, j}\right)$ elasticities (equation 3 ). Possible shocks to demand preferences during a disease outbreak would be represented by $\gamma_{i, t}$. There are no studies on the impacts of HPAI on U.S. egg consumption beyond price effects. A case study for Italian consumers by Beach et al. (2008) showed limited marginal changes in demand preferences that were short in duration (less than 5 weeks). However, U.S. consumers have been shown to be less risk averse in response to food health issues than their Italian counterparts (Harrison, Boccaletti, and House, 2004). Because of differences in consumers' perceptions, buying ability, and additional factors such as specific attitudes regarding diseases that have not been studied for U.S. consumers, the exogenous change in demand is assumed zero for this analysis.

$$
E\left(X_{i, t}-M_{i, t}\right)=E \delta_{i, t}+\varepsilon_{x-m, i, t} E P_{i, t}^{W}
$$

Net exports are a function of the world reference price $\left(P_{i, t}^{W}\right)$ and shocks to net exports $\left(\delta_{i, t}\right)$ (equation 4). Net exports are regional exports $\left(X_{i}\right)$ minus regional imports $\left(M_{i}\right)$ by product $i$ for time $t$.

$$
E I_{i, t}=\varepsilon_{I, i} E P_{s, t}
$$

Ending stocks $\left(I_{i, t}\right)$ of good $i$ are a function of the price of shell eggs for current time period $t$ and good $i$ 's stock elasticity $\left(\varepsilon_{I, i}\right)$ (equation 5 ).

$$
E k_{i, t}=E a_{k, i, t}+E q_{i, t}
$$

Egg processing capacity $\left(k_{i}\right)$ is a function the quantity demanded and the per unit derived demand by egg type (equation 6). Although there could be some asset fixity in egg processing capital, the assumption in this model is that there are marginal changes to efficiency in production given price incentives, thus allowing for processing capacity flexing.

$$
\begin{gathered}
E a_{s, i, t}-E a_{k, i, t}=-\sigma_{s, k \mid i}\left(E P_{s, t}-E r_{i, t}\right) \\
E a_{l, i, t}-E a_{k, i, t}=-\sigma_{l, k \mid i}\left(E w-E r_{i, t}\right)
\end{gathered}
$$

To represent changes that could occur in per unit factor usage, a vector of the three per unit derived demand for the factors of production included in this model $\left(a_{s, i}, a_{k, i}\right.$, and $\left.a_{l, i}\right)$ are also differentiated to link changes in the usage of these factors and their respective prices through elasticities of substitution under constant returns to scale between shell eggs and capital $\left(\sigma_{s, k \mid}\right)$, as well 
as between labor and capital $\left(\sigma_{l, k \mid i}\right)$ (Paarlberg et al., 2008). Equation 7 indicates substitutability of capital and shell egg inputs that depend on the returns to capital and returns to shell eggs. Equation 8 allows for the substitution between labor and capital. For both equations, $\left(\sigma_{l, k \mid i}\right)$ represents the elasticity of substitution between the two inputs.

$$
\theta_{s, i} E a_{s, i, t}+\theta_{l, i} E a_{l, i, t}+\theta_{k, i} E a_{k, i, t}=0
$$

Equation 9 represents an adding up contion that dictates changes to the per unit derived demand multiplied by its respective unit revenue share $\left(\theta_{s, i}, \theta_{k, i}\right.$, and $\left.\theta_{l, i}\right)$ should sum to zero.

$$
E P_{i, t}=\theta_{l, i} E w+\theta_{s, i} E P_{s, t}+\theta_{k, i} E r_{i, t}
$$

Assuming zero economic profits in production, the retail price of output egg $\left(P_{i}\right)$ is determined by the price of inputs used inroduction $(w)$, the price of shell eggs $\left(P_{s}\right)$, and returns to capital $(r)$ in equation (10). $\theta$ represents the unit revenue share for input-labor $(l)$, shell eggs $(s)$, and capital (k)-by egg type $i$.

$$
P_{i, t}^{W} E P_{i, t}^{W}=P_{i, t} E P_{i, t}+c_{i, t} E t_{i, t}
$$

The world reference price $\left(P_{i}^{W}\right)$ links net exports to U.S. domestic prices plus transportation costs $\left(c_{i}\right)$ for time $t$ (equation 11).

$$
q_{i, t} E q_{i, t}+I_{i, t-1} E I_{i, t-1}=\left(X_{i, t}-M_{i, t}\right) E\left(X_{i, t}-M_{i, t}\right)+D_{i, t} E D_{i, t}+I_{i, t} E I_{i, t}
$$

The final market clearing conditions (equation 12) ensure that the market clears such that net exports—exports $\left(X_{i}\right)$ minus imports $\left(M_{i}\right)$-domestic consumption $\left(D_{i}\right)$, and ending stocks $\left(I_{i}\right)$ in the current period $(t)$ should equal production $\left(q_{i, t}\right)$ plus begging stocks $\left(I_{i, t-1}\right)$ in the previous period. This condition holds for both table eggs and processed eggs, which expands the model to 22 equations.

\section{Disease management strategies}

Disease management strategies and model scenarios used in this analysis consist of an outbreak of HPAI originating in an egg layer house in Minnesota and contained within the Minnesota layer industry (i.e., no transboundary or state-to-state transmission). An epidemiologically explicit farm-level data set was developed specifically for Minnesota. Minnesota was selected as the study region because of its rank in production, net exporting status, and the availability of the explicit farm-level data to model a specific disease outbreak. Minnesota produced 2,814 million eggs, or $3 \%$ of total U.S. production, in 2016 making it the 11th largest egg producing state (USDA-NASS, 2017). Minnesota is a net exporter of eggs in that production minus per capita state consumption leads to excess supply that is either shipped out of the state or country. Minnesota is regionalized from the ROUS assuming separable production, consumption, and trade. Although this is a strong modeling assumption, in times of disease management a state can be regionalized by state animal health officials closing borders or through trade restrictions by importing countries as evidenced by the 2015 HPAI outbreak where there were restrictions at the state and county levels (Thompson, 2018). Importer trade restrictions are modeled to affect Minnesota's exports, and the ROUS is modeled to have reductions in state-level imports from Minnesota. Two disease management strategies are estimated for both the epidemiological and economic models: allowing for business continuity $(B C)$ and no business continuity $(N B C)$.

The epidemiological model results provide a range for the number of affected birds that are incorporated in the economic model. Epidemiological model output is disaggregated into the number of depopulated birds and the number of birds on Monitored Premises (Table 1). The number of depopulated (for both $B C$ and $N B C$ scenario) and monitored birds (for the NBC scenario) enters the economic model as calculated shocks to the quantity of shell eggs given movement restrictions, or lack thereof. These shocks are calculated using the annual eggs per laying hen 
Table 1. Summary statistics of epidemiological model output for modeled midwestern U.S. highly pathogenic avian influenza outbreak (in numbers of birds)

\begin{tabular}{|c|c|c|c|c|c|}
\hline Scenarios & & Mean & Standard Deviation & Minimum & Maximum \\
\hline \multicolumn{6}{|l|}{ Business continuity } \\
\hline Depopulated & Quarter 1 & $2,946,622$ & $3,076,405$ & 189,340 & $14,675,910$ \\
\hline Depopulated & Quarter 2 & 38,547 & 320,158 & 0 & $6,828,979$ \\
\hline Monitored & Quarter 1 & $9,283,398$ & $6,430,009$ & 746,583 & $23,229,372$ \\
\hline Monitored & Quarter 2 & 150,405 & 817,428 & 0 & $11,219,885$ \\
\hline \multicolumn{6}{|c|}{ No business continuity } \\
\hline Depopulated & Quarter 1 & $3,598,477$ & $3,721,945$ & 189,340 & $20,004,252$ \\
\hline Depopulated & Quarter 2 & 70,960 & 387,807 & 0 & $7,626,020$ \\
\hline Monitored & Quarter 1 & $9,283,398$ & $6,430,009$ & 746,583 & $23,229,372$ \\
\hline Monitored & Quarter 2 & 150,405 & 817,428 & 0 & $11,219,885$ \\
\hline Outbreak duration & Days & 42 & 17 & 12 & 216 \\
\hline
\end{tabular}

equivalency. To account for variability in epidemiological model outputs, values enter the economic model stochastically using a triangular distribution, which limits the lower end of the number of birds affected to zero. Although there could be additional costs associated with the permitting process and additional biosecurity requirements, these are excluded as they are not publicly available and are typically borne by animal health agencies, which are not included in the scope of this research. Using Simetar, the model is estimated for 500 iterations (Richardson, Feldman, and Schuemann, 2003). The average duration for the modeled HPAI outbreak is 42 days, within the first quarter. The overwhelming majority, 91\%, of the estimated outbreaks are contained within the first quarter, with $8 \%$ of outbreaks lasting into the second quarter, and less than $2 \%$ of the epidemiological model outbreaks continuing to the third quarter.

Although market price implications can extend beyond this study period, layer repopulation is an ongoing process and can reduce the duration of disease impacts. Repopulation is the process in which farms are restocked with birds to start a new cycle of production. The repopulation process typically includes young pullets moved from pullet farms to layer farms prior to full maturity, or before the onset of egg production on a replacement bird schedule. During an outbreak, these birds and increased hatching numbers are used to replenish depopulated flocks. From hatchery, maturity occurs in less than two quarters. Given that bird stocks could be substantially repopulated in this time frame, it is possible to rebuild similar flock populations that existed prior to an outbreak. For this model, the economic impacts are estimated for two quarters consistent with the epidemiological outbreak scenarios and industry repopulation potential.

\section{Data for the economic model}

Baseline data for supply and demand is collected from various USDA sources including the Agricultural Marketing Service (USDA-AMS, 2015), the Economic Research Service (USDAERS, 2013, 2015), the National Agricultural Statistics Service (USDA-NASS, 2014, 2016), and the World Agricultural Supply and Demand Estimates (USDA-ERS, 2016). Data include egg use, consumption, beginning and ending stocks, imports, exports, and egg prices for all levels of production. Exogenous shocks for the analysis are calculated as a percentage change from baseline egg production using the epidemiological model output. 
Table 2. Model estimated mean changes in highly pathogenic avian influenza economic impacts in Minnesota (\%) with and without business continuity

\begin{tabular}{|c|c|c|c|c|c|}
\hline & & \multicolumn{2}{|c|}{$\begin{array}{l}\text { Business } \\
\text { Continuity }\end{array}$} & \multicolumn{2}{|c|}{$\begin{array}{l}\text { No Business } \\
\text { Continuity }\end{array}$} \\
\hline & & Quarter & Quarter & Quarter & Quarter \\
\hline & Unit & 1 & 2 & 1 & 2 \\
\hline Shell egg price & \$/Dozen eggs & $38.4 \%$ & $15.9 \%$ & $119.2 \%$ & $41.3 \%$ \\
\hline Table egg price & \$/Dozen eggs & $22.1 \%$ & $11.0 \%$ & $63.1 \%$ & $24.3 \%$ \\
\hline Processed egg price & \$/Equivalent dozen eggs & $8.9 \%$ & $4.1 \%$ & $25.8 \%$ & $9.2 \%$ \\
\hline Production table eggs & Dozen eggs & $-6.5 \%$ & $-1.1 \%$ & $-25.3 \%$ & $-6.5 \%$ \\
\hline Production processed eggs & Equivalent dozen eggs & $-20.4 \%$ & $-8.1 \%$ & $-65.2 \%$ & $-22.3 \%$ \\
\hline Demand table eggs & Millions of dozens of eggs & $-10.6 \%$ & $-5.3 \%$ & $-30.1 \%$ & $-11.7 \%$ \\
\hline Demand processed eggs & Millions of equivalent dozens of eggs & $-3.8 \%$ & $-1.7 \%$ & $-11.2 \%$ & $-3.8 \%$ \\
\hline
\end{tabular}

\section{Results and discussion}

\subsection{Minnesota results}

Table 2 summarizes the economic impacts for Minnesota for both the business continuity $(B C)$ and no business continuity $(N B C)$ modeled scenarios. The model results are estimated distributions around each of the endogenous variables. For this exposition, the mean values are presented and discussed.

The total reduction in number of shell eggs supplied is derived from the loss of birds through depopulation and the reduction in shell egg supply because of movement restrictions. As expected, shell egg prices increase in both scenarios because of the reduction in supply. In the $B C$ scenario, the increase in shell egg price is muted as the reduction in supply is dampened. Shell eggs produced on Monitored Premises located within Control Areas are permitted to move, mitigating the losses associated with disease management. In quarter 1, the change in shell egg price is $80.8 \%$ less when compared with the $N B C$ scenario. Minnesota table egg prices were $41.0 \%$ higher, while processed egg prices were $16.9 \%$ higher with NBC. Table egg prices were affected more than processed eggs in relative terms because of changes in production, which is discussed subsequently.

Differences in prices between the $B C$ and $N B C$ scenarios are inherent in the economic model handling of flocks monitored for presence of disease. Monitored flocks are treated as birds removed from the system in the absence of business continuity (NBC scenario). With fewer birds and no exogenous change in consumers' demand, prices increase for eggs and egg products. In this case, prices are driven higher with no business continuity as a result of supply shortages. Disease management practices that provide business continuity during an outbreak decrease the reduction in supply and dampen the consumer price impact as compared with not allowing business continuity.

In addition to price changes, there were also egg quantity changes because of the combined effects of the exogenous reduction in shell egg production and the resulting model-predicted price effects. Production of table and processed eggs decreased over both quarters, consistent with a reduction in production inputs (shell eggs) with the $N B C$ scenario showing a greater reduction in production than the $B C$ scenario. Table egg and processed egg production quantities were reduced by $18.8 \%$ and $44.8 \%$, respectively, in quarter 1 when compared with the NBC scenario. The differences in these impacts are explained by how eggs are allocated in Minnesota as part of the supply chain decision-making process. Processors must choose how to allocate shell eggs to either table eggs or processed eggs. In Minnesota, processed eggs were estimated to be affected to a 
Table 3. Model estimated changes in mean highly pathogenic avian influenza economic impacts for the rest of the United States (\%) with and without business continuity

\begin{tabular}{|c|c|c|c|c|c|}
\hline & & \multicolumn{2}{|c|}{ Business Continuity } & \multicolumn{2}{|c|}{$\begin{array}{l}\text { No Business } \\
\text { Continuity }\end{array}$} \\
\hline & & Quarter & Quarter & Quarter & Quarter \\
\hline & Unit & 1 & 2 & 1 & 2 \\
\hline Shell egg price & \$/Dozen eggs & $1.7 \%$ & $1.7 \%$ & $2.5 \%$ & $2.5 \%$ \\
\hline Table egg price & \$/Dozen eggs & $3.5 \%$ & $3.5 \%$ & $3.9 \%$ & $4.0 \%$ \\
\hline Processed egg price & \$/Equivalent dozen eggs & $1.2 \%$ & $1.2 \%$ & $1.4 \%$ & $1.4 \%$ \\
\hline Production table eggs & Dozen eggs & $2.0 \%$ & $2.0 \%$ & $1.8 \%$ & $1.8 \%$ \\
\hline Production processed eggs & Equivalent dozen eggs & $0.0 \%$ & $-0.1 \%$ & $-0.5 \%$ & $-0.5 \%$ \\
\hline Demand table eggs & Millions of dozens of eggs & $-1.7 \%$ & $-1.7 \%$ & $-1.9 \%$ & $-1.9 \%$ \\
\hline Demand processed eggs & Millions of equivalent dozens of eggs & $-0.5 \%$ & $-0.5 \%$ & $-0.5 \%$ & $-0.5 \%$ \\
\hline
\end{tabular}

greater degree than table eggs, as the higher price of table eggs incentivized more eggs to be diverted to table egg production. There are industry capacity constraints included in the economic modeling framework that limit the number of eggs that can be diverted to either production process. As a result of the change in end-product prices, the quantity of eggs demanded in Minnesota decreased in both scenarios for table and processed eggs. The NBC scenario shows a greater reduction in quantity demanded than the $B C$ scenario.

\subsection{Rest of the United States results}

The price impacts for the ROUS were similar to Minnesota (Table 3). Prices for shell eggs, table eggs, and processed eggs all increased for both scenarios. However, the differences between the two scenarios were smaller than those for Minnesota: $0.4 \%$ and $0.2 \%$ for table and processed eggs, respectively, for quarter 1 . These differentials are expected to be smaller than Minnesota's, as the ROUS shocks only represent the reduction in trade with Minnesota and changes in populations and GDP. The ROUS was still able to trade egg products internationally from products with origin within the ROUS. The supplies from Minnesota that traditionally would have been exported internationally were excluded because of modeled regionalization by importers. Additionally, the minimal direct affect Minnesota has on ROUS leads to the negligible differences between quarters within each scenario.

Production changes differed for the ROUS as table egg production increased for both quarters under both $B C$ and $N B C$ scenarios. Processed egg production was estimated to decrease in the second quarter under the $B C$ scenario and for both quarters for the $N B C$ scenario. These changes in processing are attributable to increases in net exports of table eggs. As part of the market clearing conditions, it is expected that all excess eggs that are not consumed domestically be exported. Although regional consumer population changes were exogenously increased in the model to reflect actual changes in consumer population, changes in the quantity demanded for both scenarios was estimated to decline because of the higher price implying an increase in exports to trading partners to clear the market.

\subsection{Welfare effects}

Table 4 presents the changes in Minnesota producer and consumer surplus. These measures were calculated using Wohlgenant's (2013) estimation of changes in producer surplus (PS) and 
Table 4. Model estimated changes in Minnesota producer and consumer surplus and depopulation costs resulting from a simulated highly pathogenic avian influenza outbreak in Minnesota with and without business continuity (thousand \$)

\begin{tabular}{lccccc}
\hline & \multicolumn{2}{c}{ Business Continuity } & & \multicolumn{2}{c}{ No Business Continuity } \\
\cline { 2 - 3 } & Quarter 1 & Quarter 2 & & Quarter 1 & Quarter 2 \\
\hline Producer surplus change & 1,138 & 604 & 3,415 & -439 \\
\hline Depopulation costs & $-5,284$ & 0 & $-16,925$ & 0 \\
\hline Total economic impact producer & $-4,147$ & 604 & $-13,510$ & -439 \\
\hline Consumer surplus change & $-1,796$ & -855 & $-5,543$ & -263 \\
\hline Total change in welfare & $-5,942$ & -251 & $-19,053$ & -702 \\
\hline
\end{tabular}

consumer surplus (CS) when calculating a linearized partial equilibrium model. Equations 13 and 14 represent consumer and producer surplus, respectively:

$$
\begin{aligned}
\Delta C S_{i} & =-\left(1+\varepsilon_{i}\right)^{-1} P_{0} Q_{0}\left(e^{\left(1+\varepsilon_{i}\right) E P-\varepsilon_{i} \gamma}-1\right) \\
\Delta P S_{i} & =\left(1+\varepsilon_{s}\right)^{-1} P_{0} Q_{0}\left(e^{\left(1+\varepsilon_{s}\right) E P-\varepsilon_{s} \theta}-1\right),
\end{aligned}
$$

where $P_{0}$ and $Q_{0}$ are the original baseline price and quantity, $\varepsilon_{i}$ is the price elasticity of demand for the $i$ th good, $\varepsilon_{\mathrm{s}}$ is the price elasticity of shell egg supply, $\gamma$ is a demand shock, and $\theta$ is a supply shock.

For Minnesota, the total economic impact to the producer is the combination of calculated changes in producer surplus and the exogenous cost of the shocks that are imposed. ${ }^{1}$ The model does not account for the excess burden on producers infected by HPAI, which includes the explicit costs related to depopulation. The depopulation impacts are based on a conservative estimate of total depopulation costs of $\$ 0.89$ per bird, ${ }^{2}$ which includes disposal, depopulation, and cleaning and disinfection costs, multiplied by the number of depopulated birds. ${ }^{3}$

Producers with a Monitored Premises who are able to sell their products during a disease outbreak benefit from increased prices. Changes in producer surplus are positive for both scenarios and quarters, except for the quarter $2 \mathrm{NBC}$ scenario, which has a negative producer surplus. The results for the $N B C$ scenario show an additional $\$ 2.3$ million in producer surplus over $B C$ because of the steep price increase in quarter 1 . However, accounting for depopulation impacts that are not included in the producer surplus measure, total economic impact to all producers is negative for all quarters except quarter 2 of the $B C$ scenario. These calculations are based on the expected number of infected birds, which was zero for quarter 2 of the $B C$ scenario. For quarter 1, the total estimated negative change to the producer surplus in the $N B C$ scenario is $\$ 9.4$ million more than the $B C$ scenario.

Changes in consumer surplus are negative for both scenarios because of price increases and reduced supply. For quarter $1, B C$ estimates show a $\$ 3.7$ million reduction in potential losses in consumer surplus compared with $N B C$. By providing disease management that alleviates some of the supply stress, consumer surplus losses are moderated.

Total surplus effects for Minnesota are negative because of the combination of negative changes in total economic impact to producer and consumer surplus. Quarter 1 has an estimated reduced

\footnotetext{
${ }^{1}$ Producers can be compensated a fair market value for animals and products destroyed in the interest of food safety and human health concerns, but the extent of these compensations is at the discretion of state and federal agencies and beyond the scope of this analysis.

${ }^{2}$ The estimated depopulation cost of $\$ 0.89$ per bird was elicited through expert opinion within the layer industry.

${ }^{3}$ Indemnity is estimated to be the average value of a layer for weeks $20-110$, the typical life span of layer birds in commercial layer operations.
} 
total change in surplus of $\$ 5.9$ million for $B C$ and a reduction of $\$ 19.0$ million for $N B C$, a difference of $\$ 13.1$ million. The total difference for quarter 2 is $\$ 0.5$ million, because of relatively smaller disease shocks and layer repopulation. The estimated welfare impact in Minnesota by allowing business continuity during a disease outbreak is $\$ 13.6$ million, a conservative estimate given the low expected value of indemnity payments used for depopulated birds.

The ROUS has much smaller impacts in absolute dollar terms, as there were no infected birds in the scenarios. This result simplifies the welfare estimation for the ROUS, as the costs associated with depopulation do not apply. Producer surplus changes were relatively small, but positive, again because of increases in retail prices. Producers gained slightly more surplus during the $N B C$ scenario compared with the $B C$ scenario. Like Minnesota, changes in consumer surplus were mitigated when allowing for business continuity. Total surplus changes for ROUS were nominal, including marginally positive effects for the $B C$ scenario and marginally negative results for the $N B C$ scenario.

\section{Conclusions}

During a disease outbreak, business continuity planning may allow Monitored Premises that are not infected to continue moving product out of the Control Area given that they comply with increased biosecurity measures in accordance with state animal health officials and SES Plan regulatory guidance. Permitting the movement of shell eggs, which has been shown to have low risk of disease spread when complying with increased surveillance and biosecurity (USDA-APHIS, 2010), can reduce the loss in shell egg supply and minimize the resulting price changes and welfare impacts to consumers, producers, and allied agribusinesses. Although there are other factors to consider when discussing disease management, such as best management practices or additional strain on management, the economic implications of allowing for business continuity imply a social benefit for providing a mechanism for the movement of products with a negligible or low risk of disease spread.

Conservative disease management approaches such as prolonged movement restrictions can create strains in cash flows of businesses. Business continuity planning is intended to maintain income streams for producers and agribusinesses not known to be infected with HPAI. During the 2014-2015 HPAI outbreak in the United States, more than 7,800 permits, mostly for feed and egg/egg products, were issued, which reduced the financial strain on producers and consumers (Thompson and Pendell, 2016). In this study, the consumer and producer impacts on Minnesota from a simulated HPAI outbreak were estimated to be reduced by $\$ 13.6$ million by implementing the business continuity strategies. The model provides a conservative benchmark estimate of the consumer and producer effects of changing disease management practices to incorporate business continuity. The use of a proactive permitting process can alleviate some of the challenges associated with a disease outbreak and provide industry and health agencies an avenue to minimize disruptions and costs associated with the outbreak.

This analysis focused on HPAI in the U.S. poultry industry, but its implications can have a much broader reach across diseases and industries. What if the economic impacts of other foreign animal disease could be mitigated through controls and testing that minimize disease spread risk? An outbreak of a highly pathogenic disease can lead to devastating reductions in animal stocks, and costs are felt across the affected and allied industries. If the risk of spread can be estimated for different diseases and industries, it may prove valuable to forgo absolute movement restrictions and allow for business continuity during an outbreak. Livestock industries with longer restocking phases than the poultry industry could benefit from continued revenue streams during an outbreak. Although the risk estimates for the various livestock sectors have not been conducted yet, the future of animal health management may include the costs of traditional disease control practices and the potential value of alternative strategies. As evidenced by the methods employed in this study, there may be economic advantages in comparing strategies in disease management proactively. With increases in biosecurity and surveillance, and improved detection, business 
continuity may no longer be a novel strategy, but can become the norm as evidenced by this analysis and the 2014-2015 outbreak of HPAI in the United States.

Supplementary material. To view supplementary material for this article, please visit http://doi.org/10.1017/aae.2018.37

Acknowledgements. The authors thank Kamina Johnson, Phillip Paarlberg, Ann Seitzinger, and the anonymous reviewers of this paper for improving its quality and content. This material is based on work supported by the U.S. Department of Homeland Security under Cooperative Agreement Number DHS 2010-ST-061-AG0002 and the U.S. Department of Agriculture under Cooperative Agreement Number 14-9200-0374. The views and conclusions in this document are those of the authors and should not be interpreted as necessarily representing the official polices, either expressed or implied, of the U.S. Department of Homeland Security, the Institute for Infectious Animal Diseases, or the U.S. Department of Agriculture.

\section{References}

Beach, R.H., F. Kuchler, E.S. Leibtag, and C. Zhen. The Effects of Avian Influenza News on Consumer Purchasing Behavior: A Case Study of Italian Consumers' Retail Purchases. Washington, DC: U.S. Department of Agriculture, Economic Research Service, 2008.

Bell, D. California Egg Processing, Transportation, and Marketing Costs - 2000. Riverside: Cooperative Extension, University of California, Riverside, Egg Economics Update No. 239, 2001.

Djunaidi, H., and A.C.M. Djunaidi. "The Economic Impacts of Avian Influenza on World Poultry Trade and the U.S. Poultry Industry: A Spatial Equilibrium Analysis." Journal of Agricultural and Applied Economics 39, 2(2007):313-23.

Harrison, R.W., S. Boccaletti, and L. House. "Risk Perceptions of Urban Italian and United States Consumers for Genetically Modified Foods.” AgBioForum 7, 4(2004):195-201.

Hennessey, M., B. Lee, T. Goldsmith, D. Halvorson, W. Hueston, K. McElroy, and K. Waters. "Supporting Business Continuity During a Highly Pathogenic Avian Influenza Outbreak: A Collaboration of Industry, Academia, and Government." Avian Diseases 54, 1(2010):387-89.

Huang, W., A. Hagerman, and D.A. Bessler. "The Impact of Highly Pathogenic Avian Influenza on Table Egg Prices." Choices 31, 2(2016):1-7.

Johnson, K., P.L. Paarlberg, A.H. Seitzinger, S. Ott, and D. Anderson. "Analysis of Hypothetical Highly Pathogenic Avian Influenza Outbreak in Texas on the Supply Chain.” Economic Issues: Analysis and Applied Research (Livestock Marketing Information Center) 2014(December 2014):1-15.

Johnson, K.K., and D.L. Pendell. "Market Impacts of Reducing the Prevalence of Bovine Respiratory Disease in United States Beef Cattle Feedlots." Frontiers in Veterinary Science 4(2017):189.

MacDonald, J.M., and P. Korb. Agricultural Contracting Update: Contracts in 2008. Washington, DC: U.S. Department of Agriculture, Economic Research Service, Economic Information Bulletin No. 72, 2011.

Moore, K., and H. Allen. "Continuity of Business Plans for Animal Disease Outbreaks: Using a Logic Model Approach to Protect Animal Health, Public Health, and Our Food Supply.” Agriculture 3, 2(2013):253-70.

Ollinger, M., J.M. MacDonald, and M. Madison. "Technological Change and Economies of Scale in U.S. Poultry Processing." American Journal of Agricultural Economics 87, 1(2005):116-29.

Paarlberg, P.L., A.H. Seitzinger, and J.G. Lee. "Economic Impacts of Regionalization of a Highly Pathogenic Avian Influenza Outbreak in the United States." Journal of Agricultural and Applied Economics 39, 2(2007):325-33.

Paarlberg, P.L., A.H. Seitzinger, J.G. Lee, and K.H. Mathews. Economic Impacts of Foreign Animal Disease. Washington, DC: U.S. Department of Agriculture, Economic Research Service, Economic Research Report No. 57, 2008.

Richardson, J.W., P. Feldman, and K. Schuemann. Simetar. College Station: Department of Agricultural Economics, Texas A\&M University, 2003.

Seitzinger, A.H., and P.L. Paarlberg. "Regionalization of the 2014 and 2015 Highly Pathogenic Avian Influenza Outbreaks." Choices 31, 2(2016):1-8.

Stevenson, M.A., R.L. Sanson, M.W. Stern, B.D. O’Leary, M. Sujau, N. Moles-Benfell, and R.S. Morris. "InterSpread Plus: A Spatial and Stochastic Simulation Model of Disease in Animal Populations." Preventive Veterinary Medicine 109, 1(2013):10-24.

Thomas, M.E., A. Bouma, H.M. Ekker, A.J.M. Fonken, J.A. Stegeman, and M. Nielen. "Risk Factors for the Introduction of High Pathogenicity Avian Influenza Virus into Poultry Farms during the Epidemic in the Netherlands in 2003." Preventive Veterinary Medicine 69, 1-2(2005):1-11.

Thompson, J. "Effects of Regionalized Trade Restrictions on Quantity Exported during a Highly Pathogenic Avian Influenza Event." Journal of Agricultural and Applied Economics 50, 2(2018):270-89.

Thompson, J.M., and D.L. Pendell. "Proactive Risk Assessments to Improve Business Continuity." Choices 31, 2(2016):1-8. U.S. Department of Agriculture (USDA). HPAI Outbreak 2014-2015: Control Area Release. Washington, DC: USDA, 2015.

U.S. Department of Agriculture, Agricultural Marketing Service (USDA-AMS). USDA Egg Market News Report. Washington, DC: USDA-AMS, 2015. 
U.S. Department of Agriculture, Animal and Plant Health Inspection Service (USDA-APHIS). An Assessment of the Risk Associated with the Movement of Nest Run Eggs into, within, and outside of a Control Area during a Highly Pathogenic Avian Influenza Outbreak. Fort Collins, CO: USDA-APHIS, Veterinary Services, Centers for Epidemiology and Animal Health, 2010.

U.S. Department of Agriculture, Animal and Plant Health Inspection Service (USDA-APHIS). Highly Pathogenic Avian Influenza Secure Egg Supply Plan. Riverdale, MD: USDA-APHIS, Veterinary Services, 2013.

U.S. Department of Agriculture, Animal and Plant Health Inspection Service (USDA-APHIS). Layers 2013-Part I: Reference of Health and Management Practices on Table-Egg Farms in the United States, 2013. Fort Collins, CO: USDA-APHIS, Veterinary Services, National Animal Health Monitoring System, 2014.

U.S. Department of Agriculture, Economic Research Service (USDA-ERS). Income Elasticities for Food Subcategories. Washington, DC: USDA-ERS, 2013.

U.S. Department of Agriculture, Economic Research Service (USDA-ERS). International Macroeconomic Data Set. Washington, DC: USDA-ERS, 2015.

U.S. Department of Agriculture, Economic Research Service (USDA-ERS). Livestock and Meat Domestic Data: Total Poultry. Washington, DC: USDA-ERS, 2016.

U.S. Department of Agriculture, National Agricultural Statistics Service (USDA-NASS). Poultry - Production and Value 2013 Summary. Washington, DC: USDA-NASS, 2014.

U.S. Department of Agriculture, National Agricultural Statistics Service (USDA-NASS). USDA/NASS QuickStats Ad-hoc Query Tool. Washington, DC: USDA-NASS, 2016.

U.S. Department of Agriculture, National Agricultural Statistics Service (USDA-NASS). Poultry - Production and Value 2016 Summary. Washington, DC: USDA-NASS, 2017.

Vaillancourt, J.P. "Canadian Experiences with Avian Influenza: A Look at Regional Disease Control—Past, Present, and Future. Poultry Science 88, 4(2009):885-91.

Wohlgenant, M.K. “Consumer Demand and Welfare in Equilibrium Displacement Models.” The Oxford Handbook on the Economics of Food Consumption and Policy. J.L. Lusk, J. Roosen, and J.F. Shogren, eds. New York: Oxford University Press, 2013, pp. 292-318.

World Organisation for Animal Health (OIE). Handbook on Import Risk Analysis for Animals and Animal Products. Paris: OIE, 2010.

World Organisation for Animal Health (OIE). "Article 10.4.4. Country, Zone or Compartment Free from Infection with High Pathogenicity Avian Influenza Viruses in Poultry." Terrestrial Animal Health Code. Vol. 2, Recommendations Applicable to OIE Listed Diseases and Other Diseases of Importance to International Trade. Paris: OIE, $2013 \mathrm{a}, \mathrm{p} .493$.

World Organisation for Animal Health (OIE) “Article 10.9.3. ND Free Country, Zone or Compartment.” Terrestrial Animal Health Code. Vol. 2, Recommendations Applicable to OIE Listed Diseases and Other Diseases of Importance to International Trade. Paris: OIE, 2013b, pp. 515-24.

World Organisation for Animal Health (OIE). “Infection with Avian Influenza Viruses.” Terrestrial Animal Health Code. Vol. 2, Recommendations Applicable to OIE Listed Diseases and Other Diseases of Importance to International Trade. Paris: OIE, 2016a, pp. 492-507.

World Organisation for Animal Health (OIE). "Zoning and Compartmentalisation.” Terrestrial Animal Health Code. Vol. 1, General Provisions. Paris: OIE, 2016b, pp. 147-51.

Zsidisin, G.A., S.A. Melnyk, and G.L. Ragatz. "An Institutional Theory Perspective of Business Continuity Planning for Purchasing and Supply Management.” International Journal of Production Research 43, 16(2005):3401-20.

Cite this article: Thompson JM, Pendell DL, Boyer T, Patyk KA, Malladi S, and Weaver JT (2019). Economic Impacts of Business Continuity on an Outbreak of Highly Pathogenic Avian Influenza in Minnesota Egg Laying Operations. Journal of Agricultural and Applied Economics 51, 235-248. https://doi.org/10.1017/aae.2018.37 